\title{
Linking dendroecology and association genetics: Stress responses archived in tree rings associate with SNP genotypes in Abies alba (Mill.)
}

\author{
Heer, Katrin" ${ }^{* 1}$; Behringer, David ${ }^{* 1}$; Piermattei, Alma ${ }^{2,3}$, Bässler, Claus ${ }^{4}$, Fady, Bruno ${ }^{5}$; Jehl, \\ Hans $^{4}$, Liepelt, Sascha ${ }^{1}$; Lorch, Sven ${ }^{6}$; Piotti, Andrea7 ${ }^{7}$ Vendramin, Giovanni Guiseppe ${ }^{7}$, \\ Weller, Max ${ }^{6}$; Ziegenhagen, Birgit ${ }^{1}$; Büntgen, Ulf ${ }^{3,8,9}$; Opgenoorth, Lars ${ }^{6 \$}$ \\ ${ }^{1}$ Philipps-University Marburg, Faculty of Biology, Conservation Biology, Marburg, Germany \\ 2 Marche Polytechnic University, Department of Agricultural, Food and Environmental Sciences, Ancona, Italy \\ ${ }^{3}$ DendroScience, Swiss Federal Research Institute WSL, Zürcherstrasse 111, 8903 Birmensdorf, Switzerland \\ ${ }^{4}$ Bavarian Forest National Park, Freyunger Str. 2, Grafenau, Germany \\ 5 INRA, UR Ecologie des Forêts Méditerranéennes, Avignon, France \\ ${ }^{6}$ Philipps-University Marburg, Faculty of Biology, Department of Ecology, Marburg, Germany \\ ${ }^{7}$ National Research Council, Institute of Biosciences and Bioresources, Sesto Fiorentino, Firenze, Italy \\ ${ }^{8}$ Department of Geography, University of Cambridge, Downing Place, CB2 3EN Cambridge, UK \\ ${ }^{9}$ CzechGlobe, Global Change Research Institute CAS and Masaryk University, Kotlářská 2, 61137 Brno, Czech \\ Republic \\ * Both authors contributed equally to this manuscript \\ $\S$ Corresponding author: lars.opgenoorth@uni-marburg.de
}

\section{Summary}

- Genetic association studies in forest tress would greatly benefit from information on tree response to environmental stressors over time. Dendroecology can close this gap by providing such time series measurements. Here, we jointly analyzed dendroecological and genetic data to explore the genetic basis of resistance, recovery and resilience to episodic stress in silver fir.

- We used individual level tree-ring data to characterize the growth patterns of surviving silver fir (Abies alba) during the forest dieback in the 1970s and 1980s in Central Europe and associated them with SNPs in candidate genes.

- Most trees at our study sites in the Bavarian Forest experienced severe growth decline from 1974 until the mid-1980s, which peaked during the drought year of 1976. Using the machine learning algorithm random forest, we identified 15 candidate genes that were associated with the variance in resistance, resilience and recovery among trees in this period.

- With our study we show that the unique possibility of phenotypic time series archived in treerings are a powerful resource in genetic association studies. We call for a closer collaboration of dendroceologists and forest geneticists to focus on integrating individual tree level signals in genetic association studies in long lived trees.

\section{Keywords}

Candidate genes, dendrophenotypes, genetic association, random forest, silver fir, $\mathrm{SO}_{2}$ pollution 


\section{Introduction}

Genetic association studies in forest trees often focus on phenotypes related to stress events (e.g. González-Martínez et al., 2006; Budde et al., 2014), with the goal of understanding the genetic basis of stress responses in the light of global change. Episodic stress events, such as droughts and storms, are of particular interest as they are expected to significantly increase during the $21^{\text {st }}$ century due to human-induced global climate change (IPCC, 2014). However, recording plant responses to episodic stresses in natural conditions is notoriously difficult due to the unforeseeable timing of such events. Here we utilize the fact that trees archive their reaction to environmental conditions in their wood anatomical structure and annual growth rings (Fritts \& Swetnam, 1989). Phenotypic measures derived from wood cores include e.g. ring width, anatomical features, isotopic ratios or wood density, all of them available in dated time-series. We call all such traits derived from dated annual growth rings that are available as time series "dendrophenotypes" and propose that they can be a prime resource in genetic association studies. However, since classical dendrochronological studies usually discard the variation of dendrophenotypic traits among individuals as noise (Buras et al., 2016), a shift of focus towards this individual level variation is needed. In this study we present for the first time the association of SNP genotypes from stress related candidate genes with dendrophenotypes.

A prime example of an episodic stress event in Europe was marked by the forest dieback in the 1970s and 1980s (Kandler \& Innes, 1995), which has been widely attributed to air pollution, particularly $\mathrm{SO}_{2}$ and $\mathrm{O}_{3}$ emissions, in combination with a series of exceptionally dry years (Elling et al., 2009). The conifer Abies alba Mill. (silver fir) was severely affected by these conditions with large scale dieback and severe growth decline (Kandler \& Innes, 1995). This massive stress episode provides an ideal test case to trace intraspecific variation in dendrophenotypic measures and associate them with candidate genes on small spatial scales in a natural population. For this purpose we characterized the growth decline of A. alba in the 1970s and 1980s by applying the resilience concept of Lloret et al. (2011). To do so we obtained dendrophenotypes from wood cores for $193 \mathrm{~A}$. alba trees from the Bavarian Forest National Park and associated them with SNPs at candidate genes mainly related to stress reactions (Roschanski et al., 2016). Since growth as a quantitative trait is likely influenced by many genes we not only applied a single-locus approach for the genetic association, but also used a random forest analysis to capture both the marginal effect of single SNPs, as well as the combined effect of multiple SNPs on a phenotype.

Since the stress episode caused significant dieback we expect that a large majority of the surviving trees exhibit a marked growth decline in the 1970s and 1980s, but with a high level of variance among individuals regarding resistance, resilience and recovery. Further, we expect the variation in the dendrophenotypes to be associated with genetic variation in a 
number of the targeted genes, and thus, to confirm them as candidate genes for stress response. Finally, we discuss the potential of dendrophenotypes in genetic association studies for exploring the genetic basis of growth decline and resilience in episodic stress scenarios in the context of climate change.

\section{Material and Methods}

\section{Study site}

Abies alba trees were sampled and monitored in two sites in the Bavarian Forest National Park, Germany which are situated at opposite ends of an elevational gradient but within gene flow distance to maximize phenotypic variation and minimize drift effects at the same time (Lotterhos \& Whitlock, 2015). Our sampling sites were located at $770 \mathrm{~m}$ a.s.l. (Filzwald; $48.929^{\circ} \mathrm{N}, 13.406^{\circ} \mathrm{E}$ ) and $1.120 \mathrm{~m}$ a.s.I (Rachelsee; $48.975^{\circ} \mathrm{N}, 13.400^{\circ} \mathrm{E}$ ) on the southern slope of Mt. Rachel (Fig. 1). Mean annual temperature varies between $3.8^{\circ} \mathrm{C}$ and $5.8^{\circ} \mathrm{C}$ with a mean annual precipitation from 1,200 to $1,800 \mathrm{~mm}$ in the National Park (Bässler, 2004). Here, silver fir grows in mixed mountain forests in combination with Fagus sylvatica and Picea abies which is the natural vegetation at elevations below 1,150 m. At each site, 100 adult silver fir trees were georeferenced and permanently marked with numbered tags. Temperature and humidity were recorded at both sampling sites with data loggers (DK320 DM HumiLog, Drießen \& Kern, Bad Bramstedt, Germany) starting in spring 2014. The lower elevation sampling site ('low site' hereafter) is characterized by flat terrain and subjected to accumulating cold air from higher elevations, which leads to frequent late and early frost events in spring and autumn, respectively. In contrast, the sampling site at higher elevation ('high site' hereafter) is located on a steep slope surrounding the Rachel lake. The lake influences the local climatic conditions by buffering cold temperatures. Therefore, early fall and late spring frost events are less frequent and maximum temperatures are lower than at the low site. Mean temperature, however, did not significantly differ between sites during our study period (Table S1).

\section{Phenotypes from wood cores}

To obtain data on tree-ring width (TRW), we extracted two wood cores per tree at breast height with an increment borer. If trees grew on slopes, they were cored at a $90^{\circ}$ angle to the slope to avoid compression wood. After drying, intact or slightly fractured wood cores were cut with a microtome (WSL, Birmensdorf, Switzerland) to obtain a smooth surface. The contrast between earlywood and latewood was enhanced with chalk. Cores that had several fractures (14 out of 375) were mounted on wooden holders and smoothed with sandpaper. TRW was measured with a precision of $0.01 \mathrm{~mm}$ using a LINTAB digital positioning table 
whose movements were transmitted to the TSAP-Win Scientific Software (Rinntech, Heidelberg). A master series for each site using COFECHA (Grissino-Mayer, 2001) was constructed and each series was cross-dated against this master series to avoid dating errors due to missing rings. We obtained reliable data from a total of 375 cores from 193 trees.

All tree ring time series were standardized to a mean value of one to obtain a dimensionless tree-ring index (TRI) using the detrend function in the R package dpIR (Bunn, 2008; R Core Team, 2016). Based on the inspection of chronologies at the site level, we identified the years from 1974 to 1983 as the period where most trees exhibited the strongest growth decline. In the following, we refer to this period as "depression period" and to the ten years before as "reference period" (Fig. 3). For the dendrophenotypic characterization of individual trees, we determined their resistance, recovery and resilience (following Lloret et al., 2011) to possible effects of airborne $\mathrm{SO}_{2}$ pollution (Fig. 2). In this framework, resistance describes the ratio of TRI during vs. before the extreme event; recovery describes the ratio of TRI after vs. during the event; and resilience describes the ratio of TRI after vs. before the event. Based on these definitions, we calculated the following dendrophenotypic traits: (1) the steepness of the start of the depression period in 1974 (slope_73_74) was defined as the slope of the standardized TRI between the years 1973 and 1974; (2) the resistance in the depression period (resistance_dep) was defined as the ratio between the average TRI from 1964 to 1973 and the average TRI during the depression period (1974-1983); (3) the recovery after the depression period (recovery_dep) was calculated as the ratio between the average TRI in the ten years after 1983 and the average TRI during the depression period, and (4) the end of the individual growth depression (end_dep) was defined as the year when growth surpassed the level during the reference period. To calculate the latter, we compared mean TRI after 1973 in a moving window of three years to the mean growth in the reference period (Fig. 2) and determined the year when the mean of the moving window first surpassed the mean of the reference period.

In addition, we focused on the individual growth reaction in the year 1976, which has been identified as one of the driest summers in Europe (Briffa et al., 2009). We used the res.comp function in the R package pointRes (van der Maaten-Theunissen et al., 2015) to calculate (5) the recovery_1976, (6) resilience_1976 and (7) resistance_1976 of each tree towards the drought conditions in 1976. For the calculation, we considered a two-year window to take into account the already reduced growth in the two years prior to 1976 within the period of growth depression (Lloret et al., 2011). To compare dendrophenotypes between sites, we calculated mean values and corresponding standard deviations (SD) for each site and used Welch's unequal variances $t$-tests to compare them. For the genetic association, all dendrophenotypes were centered and scaled within each site to exclude confounding effects 
due to environmental and site conditions, using the scale function in the R package base with default parameters.

\section{Genotyping}

For DNA extraction, fresh needles were collected from each tree, and immediately dried on silica gel. Needles were sent to LGC Genomics (Middlesex, United Kingdom) for genotyping. Using KASP assays, we targeted 267 polymorphic and functionally annotated SNPs in candidate genes whose selection is described in detail by Roschanski et al. $(2013,2016)$. Briefly, genes were selected based on a literature search that included the keywords adaptation, candidates, drought evolution RT-PCR and selection, or based on droughtrelated Gene Ontology terms. Out of these 267 SNPs, 241 could be successfully genotyped using the KASP technology in our samples.

The dataset was initially filtered by removing SNPs that were not called correctly for the majority of the data set (> $80 \%$ missing data) because they could interfere with subsequent filtering steps. Subsequently, individuals and SNPs with more than $10 \%$ missing data, as well as monomorphic SNPs, were removed. We then selected all SNPs with a minor allele frequency $>3 \%$. All SNPs were tested for pairwise linkage disequilibrium (LD) using the Genome Variation Server 147 v. 12.00 (National Heart, Lung, and Blood Institute, http://gvs.gs.washington.edu/GVS147/index.jsp). If pairs of SNPs were tightly linked $\left(r^{2}=1\right)$ one of the SNPs was removed. This was only the case for SNPs located on the same contig of the transcriptome assembly (see Roschanski et al., 2013).

With this set of SNPs, we imputed missing genotypes using Beagle 4.1 (Browning \& Browning, 2016) without using a reference sequence. After imputation, the dataset was cleaned again using the same filtering steps as described above. Finally, all SNPs with less than five individuals per allele combination were removed from the dataset to ensure sufficient replication, resulting in 193 individuals and 130 SNPs from 103 genes.

\section{Population clustering}

As the methods we used for phenotype-genotype association are sensitive to population structure, we applied two approaches to determine whether we could detect a genetic structure within or between sampling sites. First, we used the Bayesian clustering algorithm implemented in STRUCTURE 2.3.4 (Pritchard et al., 2000) based on the admixture model with correlated allele frequencies. We set the burn-in to $10^{5}$ iterations followed by $5 \times 10^{5}$ MCMC repetitions. We conducted 10 runs for each $\mathrm{K}$ from 1 to 6 . Second, we conducted a PCA as implemented in the $R$ package adegenet (Jombart \& Ahmed, 2011). 
Genetic association analysis

For the association analysis of SNPs and dendrophenotypes, two approaches were used. First, we applied a frequently used univariate approach, namely general linear models (GLMs) as implemented in TASSEL v. 5.0 (Bradbury et al., 2007), with each SNP as the independent variable and each dendrophenotype as the response variable. For each dendrophenotype, we ran GLMs with 10,000 permutations to obtain $p$-values independent of the data distribution. The threshold for statistical significance at $5 \%$ was 0.007 after Bonferroni multiple test correction (0.05/7).

Univariate approaches only take into account a single SNP per test. However, most phenotypes are influenced by multiple genes with small effects. Thus, we also applied the machine learning algorithm "random forest" which captures both marginal and interaction effects among SNPs. In this study, we used the feature selection procedures as implemented in the R packages Boruta (Kursa et al., 2010) and VSURF (Genuer et al., 2015). A detailed description of these methods is provided in the supplement (Methods S1).

Although SNPs were already annotated for a previous publication (Roschanski et al., 2016), we repeated this step, as the information in the NCBI database is constantly updated. All SNPs that could be associated with the dendrophenotypes with more than one of the above mentioned methods were compared to known sequences from NCBl's GenBank nonredundant protein database (NR) using the translated BLAST algorithm (blastx v. 2.6.1+, Altschul et al., 1997). The best hit, based on the Expect value that provided a functional annotation, was selected for each gene and the corresponding biological process keywords were retrieved from the Gene Ontology (GO) database (UniProtKB, The UniProt Consortium, 2015).

\section{Results}

\section{Dendrophenotypes}

We obtained data on dendrophenotypes for 98 and 95 individuals from the high and low site, respectively. Almost all trees from the high plot (97\%) were affected by a growth decline, whereas only $80 \%$ of the low site individuals showed such a reaction (Fig. 4B). For end_dep we determined mean values of 1986 and 1987 for the low and high site, respectively (Fig. 4D). Individuals from the high site had significantly lower values for slope_73_74 and resistance_dep, and on average, significantly higher values for recovery_dep when compared to the low site (Fig. 2, Fig. 4, Table 1). Most trees the high site showed a marked growth decline in 1976, while trees from the low site showed, on average, no further decline which resulted in a significantly higher value of resistance_1976 (Fig. 4F). At the low site, trees already showed an increase in growth after 1976 which is reflected in the higher values 
for recovery_1976 and resilience_1976, although only the latter differed significantly between sites (Fig 4E,G).

\section{Population structure}

Neither the STRUCTURE analysis, nor the PCA provided any indication for population substructure. The visual inspection of the bar plots in STRUCTURE clearly showed that almost all individuals were assigned to both clusters in a scenario with $\mathrm{K}=2$ without any apparent pattern (Fig. S1), and Ln P (D) declined steadily with increasing K (Fig. S2). In accordance, point clouds resulting from the PCA showed no apparent difference between the sampling sites (Fig. S3).

\section{Genetic association}

The different association methods provided us with largely different numbers of SNPs associated to our dendrophenotypes (Table 2, Table S2). VSURF identified 10 to 22 SNPs for every dendrophenptypic trait with the exception of recovery_1976, for which VSURF only found one SNP. Boruta detected a lower number of SNPs, ranging from zero to six, which were also detected by VSURF in most cases. The GLM in TASSEL yielded no significant results (permutation $p$-value $<0.007$ ).

In total, 15 SNPs were jointly identified by at least two approaches. Most of these SNPs are located in genes that code for membrane proteins related to transport and stress reactions (Table 3).

\section{Discussion}

In our study, the large majority of the investigated silver fir trees in the Bavaria Forest showed a pronounced growth decline from 1974 until the mid-1980s. Growth of most trees was reduced even further during the drought year in 1976. Although we did not find differences at the genetic level between our sampling sites, the growth decline was more severe at the high site as reflected in the dendrophenotypic traits measures. When we jointly analyzed the dendrophenotypic and genetic data, and simultaneously considered the effects of multiple SNPs with a random forest approach, we found that the variation in five out of seven dendrophenotypic traits was associated to the allelic variation of SNPs in 15 candidate genes. 


\section{Dendrophenotypes}

As expected, we found a pronounced population level growth decline in the 1970s and 1980s and population level recovery thereafter, as described earlier for silver fir in southern Germany (Elling et al., 2009). While our dataset is limited to surviving trees, inventory data from the area showed that silver fir dieback was substantial in the 1970s and 1980s. For example, some forest stands in the Bavarian Forest lost more than three-fourths of 80-120 year-old silver firs (unpublished inventory data, draft of the National Park Plan 1992). Although 1976 was not detected in an analysis for so-called pointer years (Cropper, 1979), we found that the 1976 drought had a negative effect on silver fir growth, particularly at the high site. As the methods to determine pointer years take a number of prior years as reference they are likely to fail if the previous years are already marked by reduced growth. In contrast to 1976, dry years that did not coincide with the depression period (e.g. 1959, 1972, 1982 and 2003) did not have a strong effect on silver fir growth (Fig. 3). This is in line with Elling et al. (2009), who argued that $\mathrm{SO}_{2}$ pollution not only causes direct harm to silver fir trees by impeding photosynthesis and leading to the shedding of needles but that it also increases sensitivity to drought, which might be attributable to damages of the fine-root system.

In general, we observed that trees at high elevations were affected more severely during the depression period, as reflected by the generally lower resistance and resilience. However, without on-site measurements of $\mathrm{SO}_{2}$ concentrations, we can only speculate that the high site might have been more severely affected by $\mathrm{SO}_{2}$ emissions or, alternatively, that the effect was aggravated by site-specific conditions around the lake Rachel (e.g. higher air humidity).

As shown for other Central European silver fir stands, growth rates after the depression reached an unprecedented level, which is usually attributed to a combination of less dense forest structure after the dieback in the 1970s, as well as elevated nitrogen supply and increasing temperatures (Pinto et al., 2007; Elling et al., 2009; Büntgen et al., 2014). It has also been speculated that tropospheric ozone $\left(\mathrm{O}_{3}\right)$ might be a major contributor to forest decline (Krause et al., 1986; Schmieden \& Wild, 1995). However, since tropospheric $\mathrm{O}_{3}$ concentrations increased well into the 1980s, our data do not directly indicate a major influence on growth in silver fir stands in southern Germany.

\section{Dendrophenotype-genotype Association}

So far, a few studies have jointly analysed genetic and dendroecological data in natural populations to explore the relationship between basic genetic parameters and growth traits (e.g. Pluess \& Weber, 2012; King et al., 2013; Babushkina et al., 2016). None of the studies 
found a strong genetic signal related to the investigated growth traits, which could either be attributed to stronger effects of the environmental signals compared to the genetic influence on growth processes, or to a lack of adequate genetic data (e.g. loci that are relevant for the phenotypic traits considered). To take this one step further, we correlate dendrophenotypes and variation at stress response candidate genes (Roschanski et al., 2016) using a genetic association approach.

To our knowledge this is the first association study that links dendrophenotypes with SNPs in stress-related candidate genes. At our study sites, SNPs in 15 of the 103 candidate genes associated significantly with individual dendrophenotypic traits. Many of the genes were membrane proteins of the chloroplast, mitochondria or tonoplast, and thus, tightly linked to photosynthesis or chloroplast development. For example, SNPs in contigs 716 and 14580 which are associated to resistance_dep and recovery_dep, respectively, encode for stromal $70 \mathrm{kDa}$ heat shock-related protein and a proteolytic subunit of the ATP-dependent Clp protease. Both are involved in protein folding with effects on chloroplast development and function (Sjögren et al., 2006; Latijnhouwers et al., 2010). Since $\mathrm{SO}_{2}$ pollution likely has negative effects on photosynthesis (Silvius et al., 1975), genes involved in these pathways could potentially determine how individual trees cope with these extreme conditions. Two of the genes that were exclusively associated with resistance_1976 and resilience_1976 can be directly related to drought stress response: aquaporin TIP2-1 and glucan-endo-1,3-betaglucosidase. Aquaporins are regularly involved in drought response (Maurel et al., 2008; Hamanishi \& Campbell, 2011) and a similar aquaporin (TIP1-1) has already been identified as differentially expressed in response to drought stress in silver fir seedlings (Behringer et al., 2015). Glucan-endo-1,3-beta-glucosidase was previously used as a drought stress candidate gene in Pinus pinaster (Eveno et al., 2008) and was also differentially expressed in response to drought stress in silver fir seedlings (Behringer et al., 2015). Two previous studies investigated local adaptation in silver fir along altitudinal gradients in France (Roschanski et al., 2016) and Southern Europe (Brousseau et al., 2016). Both studies identified a subset of the SNPs that showed patterns of divergent selection or correlated with environmental variables. The SNPs that associated with the dendrophenotypes did not overlap with the SNP that showed evidence of directional selection in France. Yet, two of the genes that were associated with resistance_1976 and resilience_1976 (contigs 04538 and 16332), were among the SNPs that were considered to be under divergent selection in the study of Brousseau et al. (2016) which provides additional evidence that these play a role in adaptation to extreme environmental conditions.

Eight of the SNPs found in associations are synonymous. Nevertheless, these mutations might impact gene expression, and it has been shown that there is a codon bias in conifers which affects translational efficiency (De La Torre et al., 2015). 


\section{Statistical analyses of dendrophenotypes in association studies}

Generally, dendrophenotypes are often complex phenotypes influenced by many genes with small effects. Classical single locus approaches will be less powerful to detect the underlying genetic signal. Therefore, it is key to utilize approaches that simultaneously consider the effects of multiple SNPs. Here, we applied a random forest based feature selection to identify SNPs that are likely associated with certain dendrophenotypes. The Boruta algorithm provides significant results by testing if the importance of a SNP for explaining a dendrophenotype is significantly ( $\alpha=5 \%$ ) higher than the importance of the most important randomly permuted attribute, which, under the null hypothesis is only associated by chance (Kursa et al., 2010). In contrast, VSURF does not incorporate any formal statistical hypothesis-test, but selects the most important SNPs regarding the association with a specific dendrophenotype (Genuer et al., 2015). However, this does not imply a statistically significant association. Both feature selection techniques are wrappers for the random forest algorithm and, as such, the importance value is a measure for the marginal effect of a SNP, as well as the interaction effect of all SNPs under consideration. It should be mentioned, however, that the relative contribution of marginal and interaction effect cannot be directly determined. Thus, SNPs identified by random forest procedures do not represent a network and have to be viewed independently. The benefit of such analyses is, however, that the influence of all other SNPs are incorporated in the importance of any given SNP, which provides a much better representation, given that in association studies of conifers, a single SNP never explained more than $5 \%$ of the variation of a given trait (e.g. González-Martínez et al., 2006, 2008; Eckert et al., 2009).

\section{Outlook: The future of dendrophenotypes in association studies}

Episodic environmental extremes like droughts, storms or other calamities are predicted to increase in both intensity and frequency due to global climate change (IPCC, 2014). A better understanding of the response of trees to such extreme events is urgently needed in order to predict their response to future climatic conditions. The unforeseeable timing of such extreme events makes it almost impossible to integrate them in research projects with short funding periods. However, as we have clearly shown in the present work, the time series nature of dendrophenotypes permits to characterize past tree responses to climate in general as well as to particular events, such as the response to extreme episodes. In addition, wood cores can be collected with an acceptable investment of time and money in the field and allow for diverse subsequent analyses of dendrophenotypic traits. These include anatomical features such as cell wall thickness or lumen area which are considered as proxy for physiological adaptations to external factors (Carrer et al., 2016; Ziaco et al., 2016) as well as isotope 
measures, which, for example, can be used to characterize the water use efficiency of a tree (Seibt et al., 2008). Microdensitometry can supplement ring width data with information of wood density, and thereby provide a more complete picture of growth for example during extreme events (e.g. Martinez-Meier et al., 2008). All these measures can be derived for long time series or with a focus on particular years of interest, providing exciting prospects for future studies. To facilitate this kind of research dendroecologists should start to focus on individual tree signals and not discard them as noise per default. Forest geneticists on the other hand should focus on pathways and candidate genes that are potentially related to dendrophenotypes.

\section{Contributions to Manuscript or Data}

design of the research: BF, BZ, GV, KH, LO, SL, UB

performance of the research: $\mathrm{CB}, \mathrm{HJ}, \mathrm{KH}, \mathrm{LO}, \mathrm{MW}, \mathrm{SVL}, \mathrm{UB}$

data analysis and interpretation: AP, DB, KH, LO, MW, SVL, UB

writing the manuscript: AP, ANP, BF, BZ, CB, DB, GV, KH, LO, PA, SVL, SL, UB

\section{Acknowledgements}

We thank the Bavarian Forest National Park for supporting the field work. $\mathrm{KH}$ was funded by the ERAnet BiodivERsA project 'TipTree' (ANR-12-EBID-0003 granted to BZ, LO, BF, GV, $S L$ ) funded by the German Federal Ministry of Education and Research (Grant 01LC1202A to). MW and SVL were supported by ERASMUS scholarships during their stay at WSL Birmensdorf. UB received additional funding from the Ministry of Education, Youth and Sports of CR within the National Sustainability Program I (NPU I), grant number LO1415. Thanks to Lena Hellmann, Diego Galván Candela and Ricardo Ochoa Pereira for their help during field work, and to Anne Verstege for her support with tree-ring measurements.

\section{Literature}

Altschul SF, Madden TL, Schäffer AA, Zhang J, Zhang Z, Miller W, Lipman DJ. 1997. Gapped BLAST and PSI-BLAST: a new generation of protein database search programs. Nucleic Acids Research 25: 3389-3402.

Babushkina EA, Vaganov EA, Grachev AM, Oreshkova NV, Belokopytova LV, Kostyakova TV, Krutovsky KV. 2016. The effect of individual genetic heterozygosity on general homeostasis, heterosis and resilience in Siberian larch (Larix sibirica Ledeb.) using dendrochronology and microsatellite loci genotyping. Dendrochronologia 38: 26-37.

Bässler C. 2004. Das Klima im Nationalpark Bayerischer Wald -Darstellung, Entwicklung und Auswirkung. Nationalparkverwaltung Bayerischer Wald, Grafenau, Germany.

Behringer D, Zimmermann H, Ziegenhagen B, Liepelt S. 2015. Differential gene expression reveals candidate genes for drought stress response in Abies alba (Pinaceae). PLOS ONE 10: e0124564. 
Bradbury PJ, Zhang Z, Kroon DE, Casstevens TM, Ramdoss Y, Buckler ES. 2007. TASSEL: software for association mapping of complex traits in diverse samples. Bioinformatics (Oxford, England) 23: 2633-2635.

Briffa KR, van der Schrier G, Jones PD. 2009. Wet and dry summers in Europe since 1750: evidence of increasing drought. International Journal of Climatology 29: 1894-1905.

Brousseau L, Postolache D, Lascoux M, Drouzas AD, Källman T, Leonarduzzi C, Liepelt S, Piotti A, Popescu F, Roschanski AM, et al. 2016. Local adaptation in European firs assessed through extensive sampling across altitudinal gradients in Southern Europe. PLOS ONE 11: e0158216.

Browning BL, Browning SR. 2016. Genotype imputation with millions of reference samples. The American Journal of Human Genetics 98: 116-126.

Budde KB, Heuertz M, Hernández-Serrano A, Pausas JG, Vendramin GG, Verdú M, GonzálezMartínez SC. 2014. In situ genetic association for serotiny, a fire-related trait, in Mediterranean maritime pine (Pinus pinaster). New Phytologist 201: 230-241.

Bunn AG. 2008. A dendrochronology program library in R (dpIR). Dendrochronologia 26: 115-124.

Büntgen U, Tegel W, Kaplan JO, Schaub M, Hagedorn F, Bürgi M, Brázdil R, Helle G, Carrer M, Heussner K-U, et al. 2014. Placing unprecedented recent fir growth in a European-wide and Holocene-long context. Frontiers in Ecology and the Environment 12: 100-106.

Buras A, Maaten-Theunissen M van der, Maaten E van der, Ahlgrimm S, Hermann P, Simard S, Heinrich I, Helle G, Unterseher M, Schnittler M, et al. 2016. Tuning the voices of a choir: Detecting ecological gradients in time-series populations. PLOS ONE 11: e0158346.

Carrer M, Brunetti M, Castagneri D. 2016. The imprint of extreme climate events in century-long time series of wood anatomical traits in high-elevation conifers. Frontiers in Plant Science 7.

Cropper JP. 1979. Tree-ring skeleton plotting by computer. Tree-Ring Bulletin.

De La Torre AR, Lin Y-C, Peer YV de, Ingvarsson PK. 2015. Genome-wide analysis reveals Diverged patterns of codon bias, gene expression, and rates of sequence evolution in Picea gene families. Genome Biology and Evolution 7: 1002-1015.

Eckert AJ, Bower AD, Wegrzyn JL, Pande B, Jermstad KD, Krutovsky KV, St. Clair JB, Neale DB. 2009. Association genetics of coastal Douglas fir (Pseudotsuga menziesii var. menziesii, Pinaceae). I. Cold-hardiness related traits. Genetics 182: 1289-1302.

Elling W, Dittmar C, Pfaffelmoser K, Rötzer T. 2009. Dendroecological assessment of the complex causes of decline and recovery of the growth of silver fir (Abies alba Mill.) in Southern Germany. Forest Ecology and Management 257: 1175-1187.

Eveno E, Collada C, Guevara MA, Léger V, Soto A, Díaz L, Léger P, González-Martínez SC, Cervera MT, Plomion C, et al. 2008. Contrasting patterns of selection at Pinus pinaster Ait. drought stress candidate genes as revealed by genetic differentiation analyses. Molecular Biology and Evolution 25: 417-437.

Fritts HC, Swetnam TW. 1989. Dendroecology: A tool for evaluating variations in past and present forest environments. Advances in Ecological Research 19: 111-188.

Genuer R, Poggi J-M, Tuleau-Malot C. 2015. VSURF: An R package for variable selection using random forests. The $R$ Journal 7: 19-33.

González-Martínez SC, Ersoz E, Brown GR, Wheeler NC, Neale DB. 2006. DNA sequence variation and selection of tag single-nucleotide polymorphisms at candidate genes for drought-stress response in Pinus taeda L. Genetics 172: 1915-1926. 
González-Martínez SC, Huber D, Ersoz E, Davis JM, Neale DB. 2008. Association genetics in Pinus taeda L. II. Carbon isotope discrimination. Heredity 101: 19-26.

Grissino-Mayer HD. 2001. Evaluating crossdating accuracy: A manual and tutorial for the computer program COFECHA. Tree-Ring Research.

Hamanishi ET, Campbell MM. 2011. Genome-wide responses to drought in forest trees. Forestry.

IPCC. 2014. Climate Change 2014: Synthesis Report. Contribution of Working Groups I, II and III to the Fifth Assessment Report of the Intergovernmental Panel on Climate Change. Geneva,

Switzerland.

Jombart T, Ahmed I. 2011. adegenet 1.3-1: new tools for the analysis of genome-wide SNP data. Bioinformatics 27: 3070-3071.

Kandler O, Innes JL. 1995. Air pollution and forest decline in Central Europe. Environmental Pollution 90: 171-180.

King GM, Gugerli F, Fonti P, Frank DC. 2013. Tree growth response along an elevational gradient: climate or genetics? Oecologia 173: 1587-1600.

Krause GHM, Arndt U, Brandt CJ, Bucher J, Kenk G, Matzner E. 1986. Forest decline in Europe; Development and possible causes. Water, Air, and Soil Pollution 31: 647-668.

Kursa MB, Rudnicki WR, others. 2010. Feature selection with the Boruta package. Journal of Statistical Software 36.

Latijnhouwers M, Xu X-M, Møller SG. 2010. Arabidopsis stromal 70-kDa heat shock proteins are essential for chloroplast development. Planta 232: 567-578.

Lloret F, Keeling EG, Sala A. 2011. Components of tree resilience: effects of successive low-growth episodes in old ponderosa pine forests. Oikos 120: 1909-1920.

Lotterhos KE, Whitlock MC. 2015. The relative power of genome scans to detect local adaptation depends on sampling design and statistical method. Molecular Ecology 24: 1031-1046.

van der Maaten-Theunissen M, van der Maaten E, Bouriaud O. 2015. pointRes: An R package to analyze pointer years and components of resilience. Dendrochronologia 35: 34-38.

Martinez-Meier A, Sanchez L, Pastorino M, Gallo L, Rozenberg P. 2008. What is hot in tree rings? The wood density of surviving Douglas-firs to the 2003 drought and heat wave. Forest Ecology and Management 256: 837-843.

Maurel C, Verdoucq L, Luu D-T, Santoni V. 2008. Plant Aquaporins: Membrane channels with multiple integrated functions. Annual Review of Plant Biology 59: 595-624.

Pinto PE, Gégout J-C, Hervé J-C, Dhôte J-F. 2007. Changes in environmental controls on the growth of Abies alba Mill. in the Vosges Mountains, north-eastern France, during the 20th century. Global Ecology and Biogeography 16: 472-484.

Pluess AR, Weber P. 2012. Drought-adaptation potential in Fagus sylvatica: Linking moisture availability with genetic diversity and dendrochronology. PLOS ONE 7: e33636.

Pritchard JK, Stephens M, Donnelly P. 2000. Inference of population structure using multilocus genotype data. Genetics 155: 945-959.

R Core Team. 2016. R: A Language and Environment for Statistical Computing. Vienna, Austria: $\mathrm{R}$ Foundation for Statistical Computing. 
Roschanski AM, Csilléry K, Liepelt S, Oddou-Muratorio S, Ziegenhagen B, Huard F, Ullrich KK, Postolache D, Vendramin GG, Fady B. 2016. Evidence of divergent selection for drought and cold tolerance at landscape and local scales in Abies alba Mill. in the French Mediterranean Alps. Molecular Ecology: n/a-n/a.

Roschanski AM, Fady B, Ziegenhagen B, Liepelt S. 2013. Annotation and re-sequencing of genes from de novo transcriptome assembly of Abies alba (Pinaceae). Applications in Plant Sciences 1: 1200179.

Schmieden U, Wild A. 1995. The contribution of ozone to forest decline. Physiologia Plantarum 94: 371-378.

Seibt U, Rajabi A, Griffiths H, Berry JA. 2008. Carbon isotopes and water use efficiency: sense and sensitivity. Oecologia 155: 441.

Silvius JE, Ingle M, Baer CH. 1975. Sulfur dioxide inhibition of photosynthesis in isolated spinach chloroplasts. Plant Physiology 56: 434-437.

Sjögren LLE, Stanne TM, Zheng B, Sutinen S, Clarke AK. 2006. Structural and functional insights into the chloroplast ATP-dependent Clp protease in Arabidopsis. The Plant Cell 18: 2635-2649.

The UniProt Consortium. 2015. UniProt: a hub for protein information. Nucleic Acids Research 43: D204-D212.

Ziaco E, Biondi F, Heinrich I. 2016. Wood cellular dendroclimatology: Testing new proxies in great basin bristlecone pine. Frontiers in Plant Science 7. 


\section{Figures}

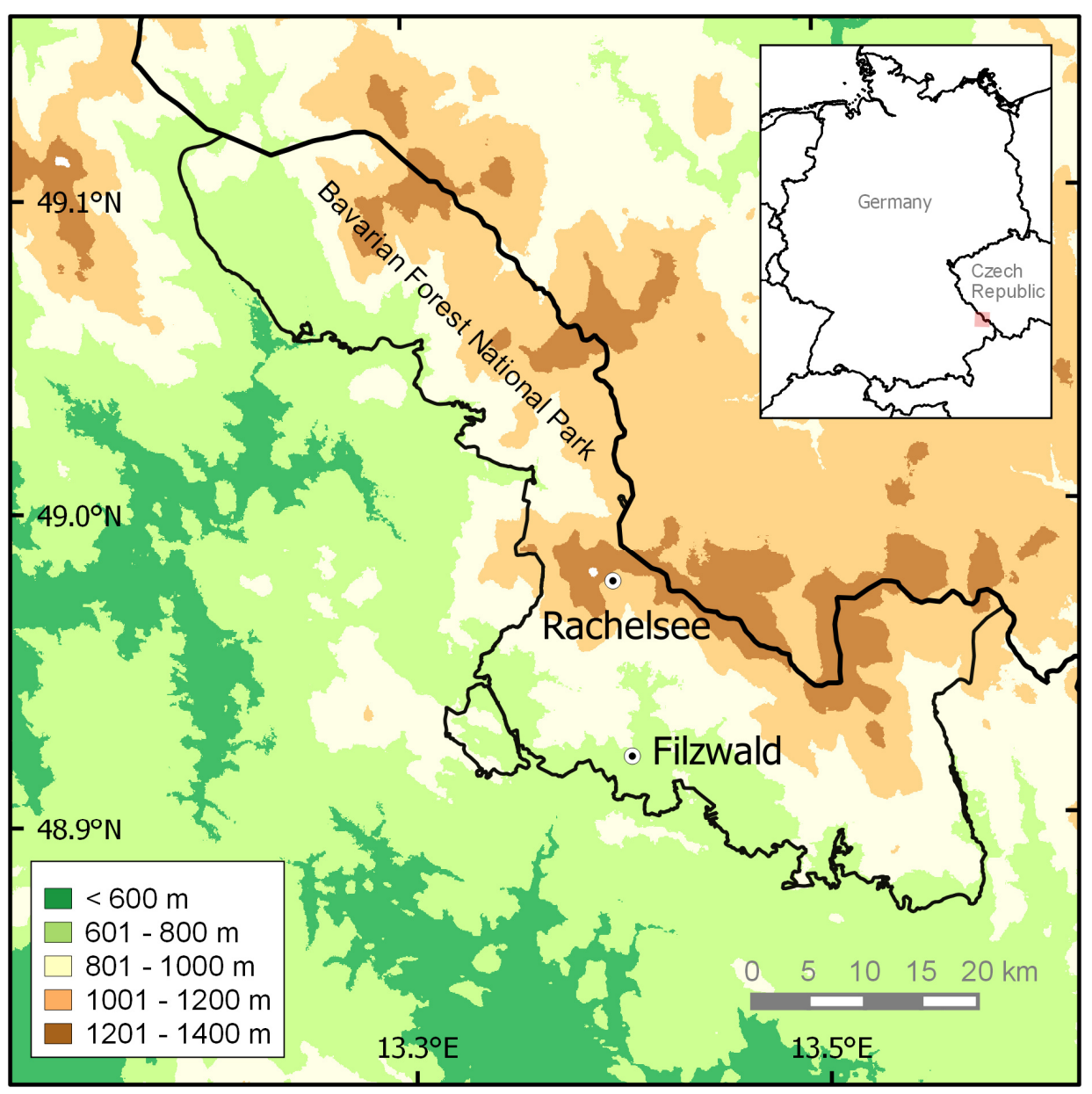

Figure 1. Study site in the Bavarian Forest National Park with the sampling sites Rachelsee ('high site', 1120 m a.s.I.) and Filzwald ('low site', 770 m a.s.l.) 


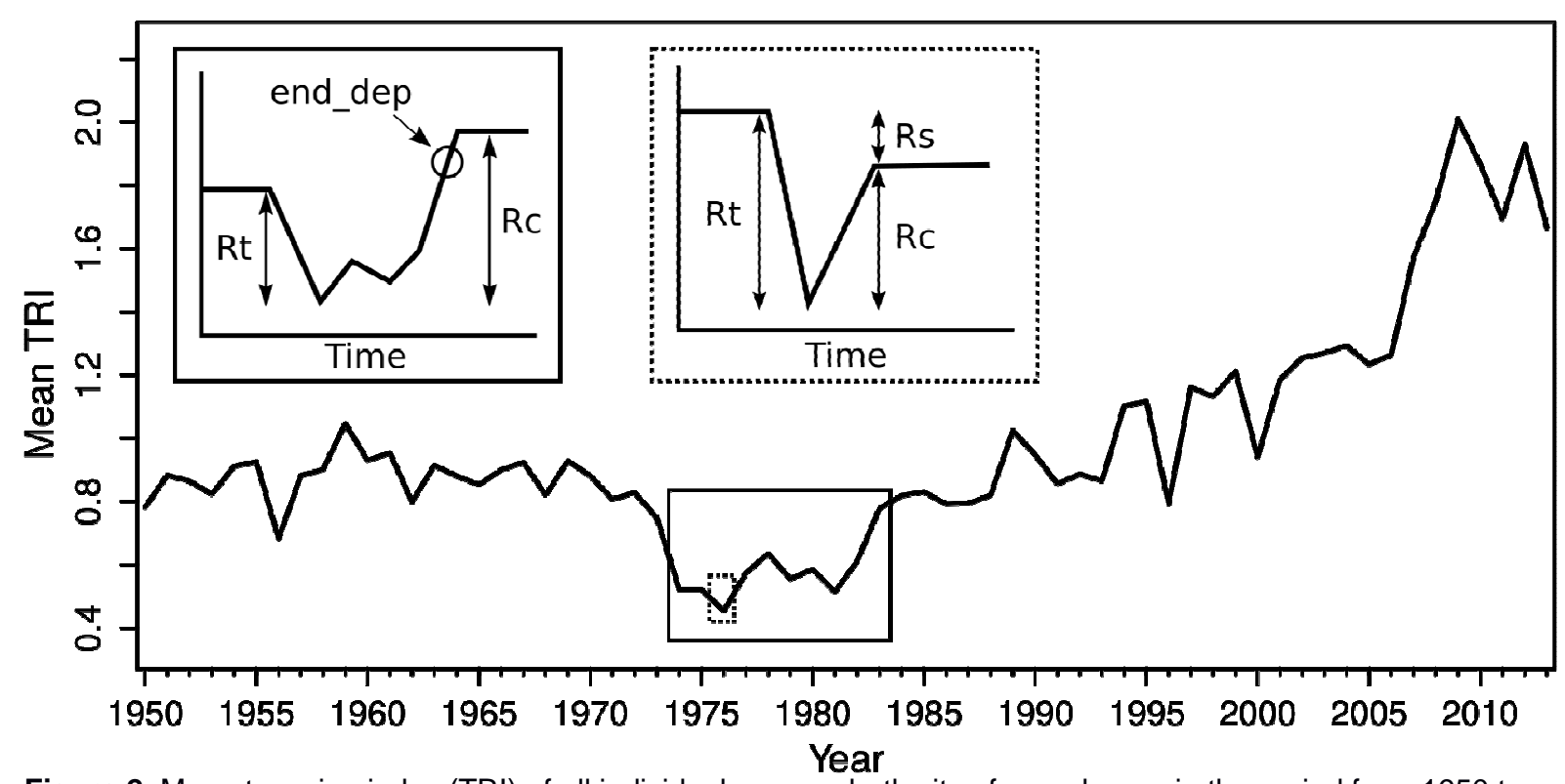

Figure 2. Mean tree-ring index (TRI) of all individuals across both sites for each year in the period from 1950 to 2013. The insets (modified after Lloret et al. 2011) are simplified graphical representations of the dendrophenotypic measures resistance (Rt), recovery (Rc), resilience (Rs) and end of depression period (end_dep) for the growth depression (solid box) and for the drought year 1976 (dashed box). For details regarding the calculation of the indices see material and methods.

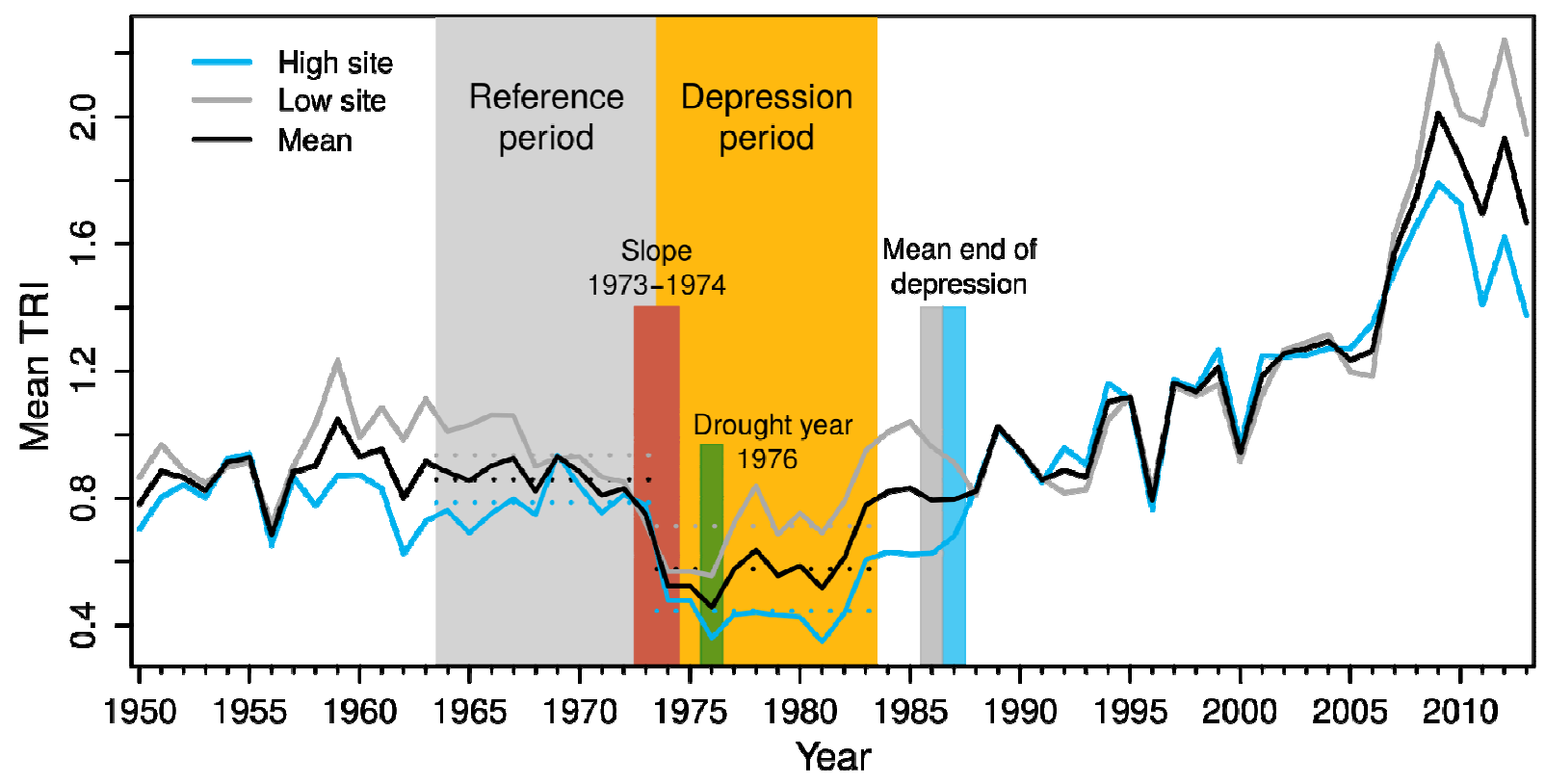

Figure 3. Mean tree-ring index (TRI) of all individuals across both sites and separated for the two sites (high and low) for each year in the period from 1950 to 2013. The shaded reference and depression period are the basis for the calculation of the resistance to $\mathrm{SO}_{2}$ pollution. Dotted lines represent the mean TRI for the corresponding period and site. Vertical bars from left to right mark the onset of the depression period for which we calculated the slope, the drought year 1976, and the mean end of the growth depression for low and high elevations, respectively. 

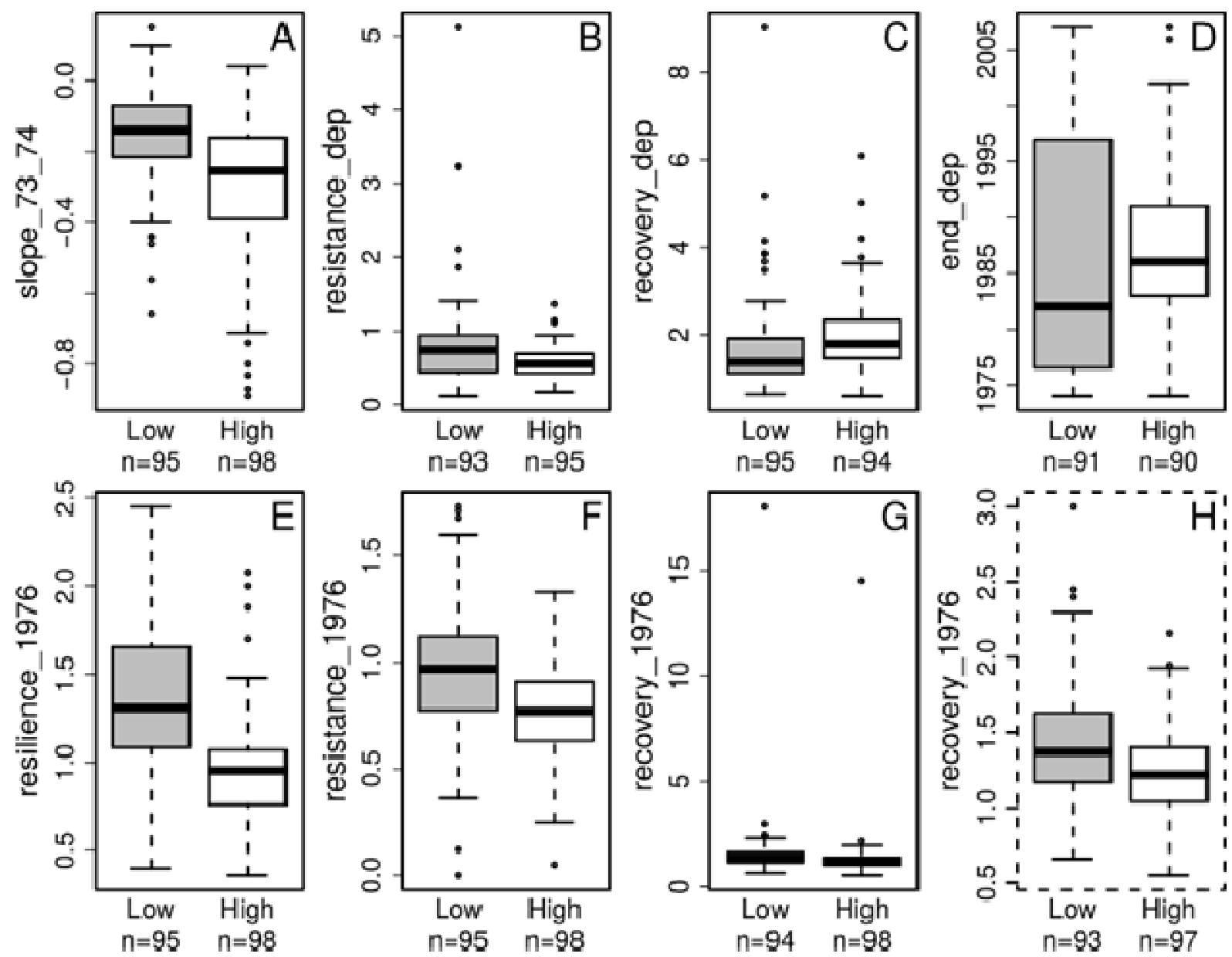

Figure 4. Dendrophenotypes for trees from both sites (Low and High). Phenotypes that describe the start (A) and end of the depression period (D), and the trees' resistance (B) and recovery (C) are depicted. Resilience (E) and resistance $(F)$ to and recovery $(G)$ from the drought year 1976 are depicted. For a better visualization of the data distributions, the extreme values for recovery_1976 were removed $(\mathrm{H})$. 


\section{Tables}

Table 1. Summary statistics for the comparison of dendrophenotypes between the two sites. Test results from a Welch's $t$-tests are provided.

\begin{tabular}{|l|l|l|l|l|l|l|l|} 
Site & slope_73_74 & resistance_dep & recovery_dep & end_dep & resilience_1976 & resistance_1976 & recovery_1976 \\
\hline Low (mean \pm SD) & $-0.15 \pm 0.13$ & $0.82 \pm 0.67$ & $1.66 \pm 1.11$ & $1986.49 \pm 11.21$ & $1.37 \pm 0.41$ & $0.97 \pm 0.30$ & $1.59 \pm 1.76$ \\
High (mean \pm SD) & $-0.30 \pm 0.20$ & $0.58 \pm 0.21$ & $1.96 \pm 0.89$ & $1987.48 \pm 6.57$ & $0.95 \pm 0.30$ & $0.76 \pm 0.22$ & $1.41 \pm 1.37$ \\
$T$ & -5.983 & -3.3264 & 2.0079 & 0.72087 & -7.9174 & -5.4393 & -0.81124 \\
Df & 169 & 109 & 179 & 146 & 171 & 173 & 176 \\
$p$-value & $<\mathbf{0 . 0 0 1}$ & $\mathbf{0 . 0 0 1 2}$ & $\mathbf{0 . 0 4 6}$ & 0.47 & $<\mathbf{0 . 0 0 1}$ & $<\mathbf{0 . 0 0 1}$ & 0.48 \\
\hline
\end{tabular}

SD: standard deviation, $t$ : $t$-statistic, df: degrees of freedom

Table 2. Overview of the results of the different association methods (Tassel GLM, Boruta and VSURF) for each dendrophenotype. Values in cells indicate the number of SNPs identified by each method for a given dendrophenotype.

\begin{tabular}{|c|c|c|c|c|c|c|c|}
\hline & slope_73_74 & resistance_dep & recovery_dep & end_dep & resilience_1976 & resistance_1976 & recovery_1976 \\
\hline VSURF & 22 & 10 & 18 & 11 & 17 & 13 & 1 \\
\hline Boruta + VSURF & 1 & 3 & 5 & 0 & 3 & 6 & 0 \\
\hline
\end{tabular}


Table 3. SNPs associated with scaled dendrophenotypes using Boruta and VSURF. Only SNPs that were associated with a given dendrophenotype with both methods are shown. A full table with all detected associations is provided in the supplementary material (Table S2). SNP IDs refer to the contigs and position of the SNP within the respective contig in the assembly of Roschanski et al. (2013). SNP type indicates whether a SNP is synonymous (syn), non-synonymous (non-syn), or located in intergenic regions. For non-

synonymous SNPs, the Amino acid change (AAC) is indicated.

\begin{tabular}{|c|c|c|}
\hline SNP ID & Protein & $\begin{array}{l}\text { Biological Process (with capital letter: GO } \\
\text { keyword) }\end{array}$ \\
\hline 00628.351 & mitochondrial arginine transporter BAC2 & Stress response, transport \\
\hline 00716.144 & heat shock $70 \mathrm{kDa}$ protein 7 , chloroplastic & Protein transport, stress response, transport \\
\hline 02190.265 & $\begin{array}{l}\text { ATP-dependent Clp protease proteolytic } \\
\text { subunit } 4 \text {, chloroplastic-like }\end{array}$ & $\begin{array}{l}\text { Chloroplast organization, regulation of timing of } \\
\text { transition from vegetative to reproductive phase }\end{array}$ \\
\hline 04538.470 & 60S ribosomal protein L7-2-like & $\begin{array}{l}\text { Cytoplasmic translation, maturation of LSU-rRNA } \\
\text { from tricistronic rRNA transcript }\end{array}$ \\
\hline 08092.366 & T-complex protein 1 subunit epsilon & protein folding \\
\hline 08855.137 & $\begin{array}{l}\text { Lhca4 protein, Type } 4 \text { protein of light- } \\
\text { harvesting complex of photosystem I }\end{array}$ & Photosynthesis \\
\hline 09197.63 & aquaporin TIP2-1 & Transport \\
\hline 10568.484 & GDP-mannose pyrophosphorylase & $\begin{array}{l}\text { Cellulose biosynthetic process, defense response } \\
\text { to bacterium, GDP-mannose biosynthetic process, } \\
\text { L-ascorbic acid biosynthetic process, response to } \\
\text { ammonium ion, response to heat, response to } \\
\text { jasmonic acid, response to ozone, response to salt } \\
\text { stress }\end{array}$ \\
\hline 12178.301 & glucan-endo-1,3-beta-glucosidase & Plant defense \\
\hline 14580.627 & $\begin{array}{l}\text { ATP-dependent Clp protease proteolytic } \\
\text { subunit-related protein } 4 \text {, chloroplastic-like }\end{array}$ & $\begin{array}{l}\text { Regulation of gene expression, response to } \\
\text { reactive oxygen species }\end{array}$ \\
\hline 15256.604 & $\begin{array}{l}\text { Ferredoxin-NADP reductase, leaf-type } \\
\text { isozyme, chloroplastic, partial }\end{array}$ & Electron transport, photosynthesis, transport \\
\hline 16332.419 & proteasome subunit beta type- 6 & $\begin{array}{l}\text { Proteolysis involved in cellular protein catabolic } \\
\text { process }\end{array}$ \\
\hline 16411.197 & $\begin{array}{l}\text { Mitochondrial carnitine/acylcarnitine carrier- } \\
\text { like protein }\end{array}$ & Transport \\
\hline 16430.504 & $\begin{array}{l}\text { NADH dehydrogenase (ubiquinone) iron-sulfur } \\
\text { protein } 7 \text {, mitochondrial }\end{array}$ & Electron transport, Respiratory chain, Transport \\
\hline 24318.117 & $\begin{array}{l}\text { LIM domain-containing protein WLIM2b } \\
\text { isoform X1 }\end{array}$ & - \\
\hline
\end{tabular}

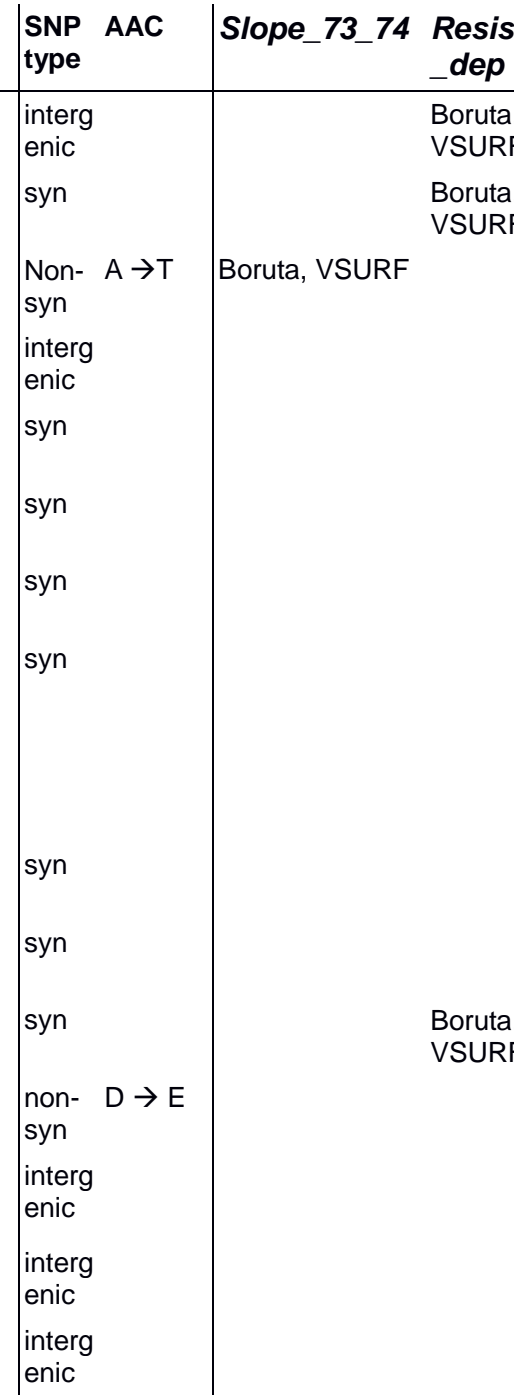

VSURF

Boruta,

SURF

ep

ce_1976_1976

VSURF

Boruta

VSURF

Boruta,
VSURF

Boruta,

VSURF

Boruta,

VSURF

Boruta,

VSURF

$\begin{array}{lll} & \begin{array}{c}\text { Boruta, } \\ \text { VSURF } \\ \text { Boruta, } \\ \text { VSURF }\end{array} & \begin{array}{l}\text { Boruta, } \\ \text { VSURF }\end{array} \\ & & \\ & & \begin{array}{c}\text { Boruta, } \\ \text { VSURF }\end{array} \\ \text { Boruta, } & & \text { Boruta, } \\ \text { VSURF } & & \text { VSURF } \\ & & \text { Boruta, } \\ & & \text { VSURF }\end{array}$

Boruta,

Boruta,
VSURF$$
\text { VSURF }
$$

VSURF 